\title{
THE STUDY OF WORKING WITH ERRORS IN EXPERIMENTAL CLASSES IN ATOMIC NUCLEUS AND ELEMENTARY PARTICLE PHYSICS
}

\author{
Maxamadi Muminovich Chariev
}

Candidate of Physical And Mathematical Sciences, Associate Professor, Department Of Theoretical Physics, Termez State University, Uzbekistan

\section{ABSTRACT}

The article pays special attention to modern methods of processing the results obtained by students in the field of atomic nucleus and elementary particle physics. In particular, many concepts of error theory and methods of error detection that students encounter while doing work are presented.

KEYWORDS:- Physical quantities, errors, systematic error, random error, absolute error, relative error, average values of quantities.

\section{INTRODUCTION}

It is known that the recently adopted Resolution of the President of the Republic of Uzbekistan "On measures to improve the quality of education in physics and the development of scientific research" dated March 19, 2021 No PP5032 sets tasks to improve the quality of teaching physics [1]. Therefore, in writing this article, the author aims to improve the quality and effectiveness of teaching physics and will be a worthy help to students working with errors in experimental lessons in physics.

Experimental lessons play an important role in the study of atomic nucleus and elementary particle physics. The laws of physics are determined experimentally and verified experimentally. Students learn basic physical phenomena and processes in experimental classes. In general, the following goals are set for conducting a physics course:

a) to help future physicists to better understand the basic laws of physics and phenomena;

b) to teach students to be creative in their research work, to choose the right method of experimentation, to measure the values of physical quantities and to check them by means of formulas;

c) acquaintance with modern equipment and methods of mathematical development of physical measurement results. This general goal is achieved in different ways in each particular case, depending on the level of knowledge of the students in the physics 
CURRENT RESEARCH JOURNAL OF PEDAGOGICS 2(11): 209-214,

November 2021 DOI: https://doi.org/10.37547/pedagogics-crjp-02-11-38

ISSN 2767-3278

(C)2021 Master Journals

Crossref doi) 81 Google

Accepted 25th November, 2021 \& Published 30 ${ }^{\text {th }}$ November, 2021

practicum and the level of equipment of the practicum.

The issues facing students in the physics practicum can be broadly divided into the following three options:

1. The student is shown the most optimal method of measuring physical size and a set of measuring instruments.

2. The measurement method is specified, but the student selects the necessary instruments for the measurement method.

3. The student is instructed to measure a certain physical quantity with the specified accuracy. The student chooses the method and measuring instruments that will best solve the problem.

One of the main goals of the physics practicum is to teach a particular measurement method and the correct analysis and interpretation of measurement results.The data obtained in the experiment will always have an error. This error is mainly caused by experimental conditions, imperfections in the measurement method and physical instruments. It is only when a measurement error is indicated that the measurement result, i.e. the data obtained, begins to take on a certain meaning. The result of an experiment developed in this way can be compared with theoretical data or tabular data. Mastering the methods of error detection described here is not enough to complete the task successfully. The point is that it is very important to be able to choose from a number of methods of error calculation that accurately and clearly reveal the physical nature of a particular experiment. This creative process requires a certain amount of reading, meticulousness, logical analysis skills from the student.

Measurement of physical quantities. Physics collects information about events in the material world that surrounds us through experiments.
In a laboratory setting, a physical experiment is performed to study the effect of a factor on a particular event. In order to fully reveal the properties of objects and the nature of phenomena, it is necessary to include certain physical quantities that characterize these properties, and with their help to quantify various qualitative aspects. In that case, the relationship between the different properties of the phenomenon is reflected through the relationship between the physical quantities. Physical quantity is a quantity that quantifies a quality. Any process can be mathematically expressed using physical quantities. Therefore, it is especially important to observe physical processes and measure different physical quantities. Measuring a physical quantity consists of comparing it with a quantity taken as a reference. Measurements can be divided into two:

- direct measurement,

- indirect measurement.

In direct measurement, the physical quantity measured is compared directly with the standard or with measuring instruments graded in the appropriate unit. Examples of direct measurements are the measurement of a distance with a ruler, a caliper, the measurement of temperature using a thermometer, and the measurement of current and voltage, respectively, using an ammeter and voltmeter. The value of the measured quantity is calculated directly on the scale of the instrument or the number of sections on the scale is determined and multiplied by its value equal to one unit.

The magnitude detected in indirect measurement is determined from the functional relationship between the quantities that can be measured directly [2-3]. For example, to measure the velocity of a straight line, the path $S$ and the time $t$ traversed in a given time interval are directly measured, and then the velocity is 
CURRENT RESEARCH JOURNAL OF PEDAGOGICS 2(11): 209-214,

November 2021 DOI: https://doi.org/10.37547/pedagogics-crjp-02-11-38

ISSN 2767-3278

(C)2021 Master Journals

Crossref doi) 81 Google

Accepted 25th November, 2021 \& Published 30 ${ }^{\text {th }}$ November, 2021

calculated from the $=\mathrm{s} / \mathrm{t}$ relationship between them. It is also used to directly measure the mass $\mathrm{m}$ of a body and the volume $\mathrm{V}$ to determine the density of the body, and then calculate the density from the $\mathrm{m} / \mathrm{V}$ bond between them.

To determine the physical size, the following steps must be performed:

1) installation and inspection of instruments;

2) monitor and record instrument readings;

3) calculation of the physical quantity to be determined using the results of measurements;

4) error calculation.

The approximate value of the physical magnitude is determined in any measurement because of the natural error of the experimental sensory organs and the imperfection of the measuring instruments. This means that any measurement can only be performed with a certain degree of accuracy. For example, if the thickness of the plate is measured with an accuracy of $0.1 \mathrm{~mm}$ using a caliper, the actual thickness of the plate does not differ by more than $0.1 \mathrm{~mm}$ from the measured thickness. The accuracy of the measurement is determined primarily by the accuracy of the measuring instrument. Physical size cannot be measured with greater accuracy than instrument accuracy. The accuracy of an instrument is characterized by the smallest fraction of its scale, which determines the degree to which the value found approaches the true value of the measured quantity. The accuracy of the instrument is given by the class of the instrument and is indicated in its passport.

In some measurements, the error of the instrument depends on its accuracy. This error is \pm 0.5 of the smallest percentage that can be calculated from the instrument scale. For example, if the smallest fraction of the thermometer scale is 0.2 , its error is \pm 0.1 , while the smallest stone mass when measured on a scale is $10 \mathrm{mg}$. The error of the scales is taken in mg. The more accurate the tool, the less error.

We cannot change the accuracy of a measurement by increasing the accuracy of the calculation obtained from the scale of the measuring instrument. For example, when measuring the length of a pencil using a ruler divided by centimeters, we cannot change the accuracy of the ruler by looking at its scale with a magnifying glass.

In each laboratory work, different physical quantities are measured with different accuracy. The accuracy of one measurement affects the accuracy of others. Therefore, before measuring an indirectly determined physical quantity, it is necessary to know exactly the measurement error that has the greatest impact on its accuracy. If the physical quantity is measured with different accuracy, there is no need to try to increase the accuracy of some measurements from the accuracy of the measured quantity with the least accuracy. To increase the accuracy of the final result, any physical quantity must be measured several times, not once under the same experimental conditions.

Types of errors. Any measurements are always made with some error. These errors are divided into two groups - systematic and random errors [4-5].

1. Systematic error. A systematic error is an error that always exists. Errors resulting from incorrect installation of the instrument (error due to the accuracy of instrument preparation) and incorrect choice of measurement method are systematic errors. These errors are also caused by some external factors, such as uneven leveling of the ruler scale, non-compliance of the thermometer zero with the actual zero temperature, non-uniformity of the thermometer capillary cutting surface along the capillary, noncompliance of its shaft with the zero of the 
CURRENT RESEARCH JOURNAL OF PEDAGOGICS 2(11): 209-214,

November 2021 DOI: https://doi.org/10.37547/pedagogics-crjp-02-11-38

ISSN 2767-3278

(C)2021 Master Journals

Crossref doi) 81 Google

Accepted 25th November, 2021 \& Published 30 ${ }^{\text {th }}$ November, 2021

ammeter. In measuring the volume of liquids and gases, their volume decreases due to changes in temperature; when the mass is measured, a systematic error is made due to the fact that the object being measured is affected by the repulsive force exerted by the air on the scales and the calorimetric measurements do not take into account the heat exchange of the instrument with the external environment.

A systematic error is made when taking the values of some physical quantities from a table, rounding them up, as well as the approximate values of some constants included in the formula. For example, instead of taking $\pi=3.14159265$, $\pi=3 ; \pi=3.1 ; \pi=3.14 ; \pi=3.142$, instead of taking as for the refractive index of water $\pi=1.3$; Even if we take $\pi=1.33$, we will still make a systematic error each time. Systematic errors occur for obvious reasons, and their magnitude may remain unchanged in repeated measurements or may change according to a certain law. This error can be reduced by modifying the measurement method, making corrections to the instrument readings, and taking into account systemically influencing external factors.

2. Random sizes. Random errors are errors that occur for random reasons that are difficult to predict in advance and that affect each measurement differently. For example, in electrical measurements, we make random errors due to changes in mains voltage, uneven thickness when measuring plate thickness, insufficient illumination of the instrument scale in measurements, poor placement of instruments on the table, and natural imperfections of our sensory organs. Because of these errors, different values are obtained when measuring a physical quantity several times.

Although it is not possible to eliminate the random error in some measurements, using the mathematical theory of random events, it is possible to determine the expression that is most suitable for reducing the effect of this error on the measurement result and calculating the error magnitude. To reduce the random error, the physical quantity being determined must be measured repeatedly, not once. If the random error is greater than the systematic error, it is necessary to reduce the random error and increase the number of measurements so that it is at the same level as the instrument error.

In addition to systematic and random errors, there are also gross errors. A gross error occurs due to incorrect execution of observations and measurements. Such results should not be taken into account in the calculation. This error stems from a careless calculation of the scale, a fragmentary recording of the results. To eliminate such gross errors, it is necessary to revise the recordings and repeat the measurements. The only way to eliminate rough error in any measurement is to repeat the measurement with great care and attention.

Average values of physical quantities. Absolute error.

Of the $X_{1}, X_{2}, X_{3} \ldots X_{n}$ values found as a result of measurements of a physical quantity, the closest to the true value is

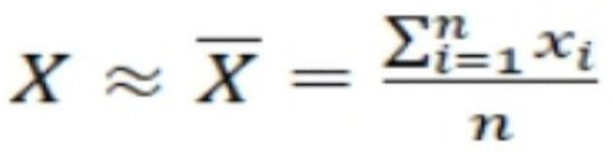

determined from the expression, where $\mathrm{n}$ is the number of measurements.

The values found during the measurements differ from each other, and their difference from the mean value is called the absolute error of some measurements. The smaller the absolute error of the measurement, the more accurately the measurement is considered to have been performed. Gross errors that differ significantly 
CURRENT RESEARCH JOURNAL OF PEDAGOGICS 2(11): 209-214,

November 2021 DOI: https://doi.org/10.37547/pedagogics-crjp-02-11-38

ISSN 2767-3278

(C)2021 Master Journals

Crossref doi) 81 Google

Accepted 25th November, 2021 \& Published 30 ${ }^{\text {th }}$ November, 2021

from the mean are omitted when calculating the error.

If, as a result of $\mathrm{n}$ repeated measurements $\Delta \mathrm{X}_{1}$, $\Delta \mathrm{X}_{2} \ldots, \Delta \mathrm{X}_{\mathrm{n}}$ absolute errors occur, the average absolute error of the measurements is equal to the arithmetic mean of the absolute values of these errors:

$$
\overline{\Delta X}=\frac{\sum_{i=1}^{n}\left|\Delta x_{i}\right|}{n}
$$

Naturally, the true value of the physical quantity is from the average value found $\pm \Delta \mathrm{X}$ varies up to, namely:

$$
X=\overline{\mathrm{X}}+\overline{\Delta X} \text {. }
$$

The student may be interested in why the number of measurements was chosen in this way. In selecting the number of measurements, care should be taken to ensure that the average absolute error that occurs in that number of measurements is not greater than the instrument error. However, in some cases, external factors affecting the measurement result do not allow the average absolute error of the physical magnitude to be reduced from the error entered by the measuring instrument, even when the number of measurements is sufficiently large. In such cases, the number of measurements is determined by the laboratory conditions and it is necessary to obtain the average absolute error of the measurement for the error of the detected magnitude. Conversely, the random errors that occur during measurements are very small, and no matter how many times we repeat the measurements, the differences between the values found will not be greater than the error entered by the measuring instrument. In such cases, the student is advised to take an instrument error or half of it for a specific measurement error. To do this, the student must perform several control measurements and be satisfied that the said condition is occurring [68].

Relative error. If it is necessary to measure a number of physical quantities during an experiment, it will be necessary to determine the measurement error for each of them. However, since we know the absolute error of each quantity, it is not possible to compare them because the quantities are not homogeneous.

\section{Conclusions}

The study of physics through experiments plays an important role in consolidating the theoretical knowledge passed. Through experiments, pupils and students discover the mysteries of nature for themselves once again. As they strengthen their knowledge of physics, they become more confident in the authenticity of the knowledge they have acquired. Therefore, it is not necessary to talk about the effectiveness of a physics lesson without experimental lessons. Experimental lessons introduce the student more closely to the adults. New aspects of their quantity, unity, and use open up in the reader's imagination. All this raises the role of experimental lessons even higher.

In practice, a student who measures physical quantities with his or her own hands becomes more interested in physics lessons. The reader begins to imagine the degree of accuracy of the sizes. This allows them to understand and evaluate errors. The student who understands the errors will also try to perform the measurements more accurately. This serves to improve the quality of the knowledge they have acquired.

\section{ReFERENCES}

1. Resolution of the President of the Republic of 
CURRENT RESEARCH JOURNAL OF PEDAGOGICS 2(11): 209-214,

November 2021 DOI: https://doi.org/10.37547/pedagogics-crjp-02-11-38

ISSN 2767-3278

(C)2021 Master Journals

Crossref dof 81 Google

Accepted 25th November, 2021 \& Published 30th November, 2021

Uzbekistan No. PP-5032 of March 19, 2021

"On measures to improve the quality of education and development of scientific research in the field of physics."

2. Iveronova V.I. Workshop on physics, "Mechanics and molecular physics", T .: Teacher, 1973.

3. Зайдель А.Н. Элементарные оценки ошибок измерений, М.:, Наука, 1968.

4. Nazirov E.N., Khudoiberganova Z.A., Safiullina N.X. Practical lessons in mechanics and molecular physics, T .:, Uzbekistan, 2001.

5. Гольдин Л.Л. Руководство к лабораторным занятиям по физике, М.:, Наука, 1973.

6. Агекян Т.А. Основы теории ошибок для астрономов и физиков, М.:, Наука, 1968.

7. Сквайрс Дж. Практическая физика, М.:, 1971.

8. Резников 3.М. Прикладная физика, М.:, Просвещение, 1989. 